\title{
Silica Sulfuric Acid as a Mild and Efficient Reagent for the Acetylation of Alcohols in Solution and under Solvent Free Conditions
}

\author{
Farhad Shirini, ${ }^{*}$ Mohammad Ali Zolfigol, and Kamal Mohammadi \\ Deparment of Chemistr, Facult of Science, Gulan Chiversity Rasht 41335 . Iran \\ Deparment of Chemistry, College of Science, Bu-Ali Sina Lniversin, Hamadan 65174. Iram \\ Recened November 3,2003
}

Key Words : Acetic anhỵdride. Acetylation. Silica sulfuric acid. Solvent free conditions

The conversion of alcohols to esters is an important synthetic transformation that has received considerable attention. ${ }^{1.2}$ Conversion of an alcohol to the corresponding acetate is typically carried out using acetic anhydride or acetyl clloride in the presence of pyridine or triethylamine as a cataly st. ${ }^{3} 4$-(Dimethylamino) pyridine is known to cause a remarkable rate acceleration in the reaction. In addition to catalysis by tertiary anines. Lewis acids have also been reported to catalyze the acetylation of alcohols. Examples include TMSCl${ }^{6} \mathrm{MgBr}_{2}{ }^{7} \mathrm{Sc}(\mathrm{AcO})_{3}-\left(\mathrm{CF}_{3} \mathrm{SO}_{2}\right)_{2} \mathrm{NH}_{3}{ }^{8} \mathrm{TiCl}_{4}+$ $\mathrm{AgClO}_{4},{ }^{9} \mathrm{CoCl}_{2}{ }^{11}$ as well as $\mathrm{Sn}(\mathrm{OTf})_{2}, \mathrm{Cu}(\mathrm{OTf})=$ and In(OTf $)_{3}{ }^{11.13}$ A highly efficient catalyst. $\mathrm{Sc}(\mathrm{OTf})_{3}$, was introduced by Yamamoto. ${ }^{14}$ However most of the reported methods suffer from one or more of the following disadvantages: long reaction time. vigorous reaction conditions. the occurance of side reactions and unavailability of the reagents, as well as poor yields of the desired product. Thus. there is still a demand to develop new and mild methods for the acetylation of alcohols in the presence of inexpensive and bench top reagents.

On the other hand, any reduction in the amount of sulfuric acid needed and / or any simplification in handling procedures is required for risk reduction. economic advantage and environment protection. ${ }^{15}$ In addition. there is current research and general interest in heterogeneous systems because of the importance such systems have in industry and in developing technologies. ${ }^{10}$

In continuation of our work on the application of silica sulfuric acid. ${ }^{17.01}$ as a new sulfuric acid function immobilized on the surface of silica gel via covalent bonding, we report here a mild. clean. simple and efficient method for the acetylation of alcohols with acetic anhydride in the presence of this reagent in solution and under solvent free conditions (Schente 1)

\section{$\mathrm{A}$ or $\mathrm{B}$}

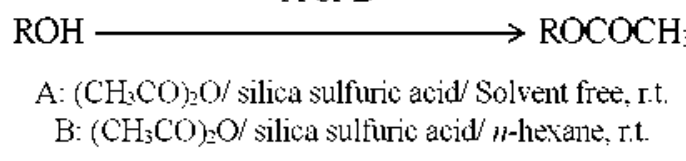

Scheme 1

\footnotetext{
${ }^{*}$ To whom correspondence should be addressed. Fax: + 98131 3220066, e-mail: shirini à guilan ac.ir
}

Acetylation of different types of alcohols including primary, allylic. benzylic, hindered and unhindered secondary and sterically hindered tertiary alcohols. was investigated in the absence of solvent by $\mathrm{Ac}_{2} \mathrm{O}$ in the presence of silica sulfuric acid (Table 1). It is in general known that diarylcarbinols can easily dimerize or dismutate in the presence of a Lewis acid catalyst. ${ }^{21}$ However, benzlyydrol itself. as a model compound. was acetylated in $90 \%$ yield using $\mathrm{Ac}_{2} \mathrm{O}$ in the presence of silica sulfuric acid without any dimerization (Table 1, entry 8). The secondary alcohols 1-phenylethanol, 1-phenyl-2propanol, cyclohexanol, (-)menthol and 2-adamantol were acetylated under the same conditions in good to excellent yields (Table 1 . entries $7.10,12.14,18$ ). It is notewortly that in the case of optically active alcohols the reaction proceeded well with complete retention of configuration (Table 1, entry 14). Interestingly. hindered tertiary alcohols such as l-methylcyclohexanol. tert-butyl alcohol and 1 -adamantol were also converted to the corresponding acetates at room temperature in good to excellent yields as models for acetylation of tertiarty alcohols (Table 1 . entries 15-17).

In order to compare the obtained results with those obtained in solution, we studied the acetylaion reaction in $n$ hexane. As shown in Table, there are appreciable difference between the results obtained in solution and those in solvent free conditions. Thus. by ommiting the solvent, in addition to ease of the work-up procedure. the reaction time was reduced and the need for solvent is avoided.

In conclusion. we have developed an efficient and excellent yielding method for the acetylation of alcohols with acetic anlydride under mild reaction conditions. The reactions are clean and no detectable by-product was found The products are obtained good to high yields and the procedure is easy.

\section{Experimental Section}

General. Chemicals were purchased from Fluka. Merck and Aldrich chemical companies. Yields refer to isolated products. Silica sulfuric acid was synthesized according to our previously reported procedure. ${ }^{17,18}$ Products were characterized by their physical constants, comparison with authentic samples and IR and NMR spectroscopy.

General procedure for the acetylation of alcohols in n- 
hexane. A mixture of alcohol ( $1 \mathrm{mmol})$, acetic anhydride $(1.5 \mathrm{mmol})$ and silica sulfuric acid $(0.05 \mathrm{~g})$ in $n$-hexane (3 $\mathrm{mL}$ ) was stirred at room temperature. The progress of the reaction was monitored by $[\mathrm{LC}$ or $\mathrm{GC}$. After completion of the reaction, solvent was evaporated and water was added $(10 \mathrm{~mL})$. The mixture was extracted with $\mathrm{CH}_{2} \mathrm{Cl}_{2}(2 \times 10$ $\mathrm{mL}$ ). The organic layer was separated, and washed with saturated $\mathrm{NaHCO}_{3}(2 \times 12 \mathrm{~mL})$ and water $(7 \mathrm{~mL})$ and dried over anhydrous $\mathrm{MgSO}_{4}$. Evaporation of the solvent followed by column chromatography on silica gel afforded the pure acetate.
General procedure for the acetylation of alcohols under solvent free conditions. A mixture of alcohol (1 mmol), acetic anhydride ( $1.5 \mathrm{mmol}$ ) and silica sulfuric acid $(0.05 \mathrm{~g})$ was stirred at room temperature. The progress of the reaction was monitored by $\mathrm{CLC}$ or $\mathrm{GC}$. After completion of the reaction, water was added $(10 \mathrm{~mL})$. The mixture was extracted with $\mathrm{CH}_{2} \mathrm{Cl}_{2}(2 \times 10 \mathrm{~mL})$. The organic layer was seperated, and washed with saturated $\mathrm{NaHCO}_{3}(2 \times 12 \mathrm{~mL})$ and water $(7 \mathrm{~mL})$ and dried over anhydrous $\mathrm{MgSO}_{4}$. Evaporation of the solvent followed by column chromatography on silica gel afforded the pure acetate.

Table 1. Acetylation of alcohols using $\mathrm{Ac}_{2} \mathrm{O}$ in the presene of silica sulfuric acid

\begin{tabular}{|c|c|c|c|c|c|c|}
\hline \multirow[t]{2}{*}{ Fintry } & \multirow[t]{2}{*}{ Subsirate } & \multirow[t]{2}{*}{ P'roduct } & \multicolumn{2}{|c|}{$\begin{array}{c}\text { Acctylation in the absence of } \\
\text { solvent }\end{array}$} & \multicolumn{2}{|c|}{ Acetylation in solution } \\
\hline & & & lime (mins.) & Yield\% & lime (min.) & Yield\% \\
\hline 1 & $\mathrm{C}_{1} \mathrm{Il}_{4} \mathrm{Cll}_{2} \mathrm{OH}$ & $\mathrm{C}_{6} \mathrm{H}_{5} \mathrm{Cl}_{2} \mathrm{OAC}$ & 4 & 90 & 10 & 85 \\
\hline 2 & $2-\mathrm{HCC}_{41} \mathrm{H}_{3} \mathrm{Cll}_{2} \mathrm{OH}$ & $2-\mathrm{BrC}_{1} \mathrm{II}_{\mathrm{I}} \mathrm{Cl}_{2} \mathrm{OAC}$ & 3 & 82 & 5 & 80 \\
\hline 3 & $2-\mathrm{ClC}_{0} \mathrm{Il}_{\mathrm{l}} \mathrm{ClI}_{2} \mathrm{OlI}$ & $2-\mathrm{ClC}_{6} \mathrm{H}_{6} \mathrm{Cll}_{2} \mathrm{O} \mathrm{AC}$ & 1 & 85 & 25 & 90 \\
\hline 4 & $4-\mathrm{ClC}_{0} \mathrm{Il}_{1} \mathrm{ClI}_{2} \mathrm{OlI}$ & $4-\mathrm{ClC}_{6} \mathrm{H}_{-1} \mathrm{Cll}_{2} \mathrm{OAC}$ & 1 & 95 & 15 & 89 \\
\hline 5 & $4-\left(\mathrm{Me}_{3} \mathrm{CCC}_{2} \mathrm{Il}_{1} \mathrm{CH}_{2} \mathrm{OlI}\right.$ & $4-\left(\mathrm{Me}_{3}\right)_{3} \mathrm{CC}_{6} \mathrm{HI}_{6} \mathrm{Cll}_{2} \mathrm{OAC}$ & 1 & 90 & 10 & 92 \\
\hline 6 & $3-\mathrm{NO} \mathrm{C}_{2} \mathrm{C}_{1} \mathrm{H}_{3} \mathrm{Cl}_{2} \mathrm{OHI}$ & $3-\mathrm{NO}_{2} \mathrm{C}_{6} \mathrm{H}_{6} \mathrm{Cl}_{2} \mathrm{OAC}$ & 5 & 82 & 10 & 80 \\
\hline 7 & & & 3 & 87 & 5 & 90 \\
\hline 8 & & & 2 & 90 & 5 & 85 \\
\hline 9 & & & 1 & 80 & 30 & 80 \\
\hline 10 & & & 1 & 85 & 10 & 82 \\
\hline 11 & & & 1 & 90 & 10 & 85 \\
\hline 12 & & & 7 & 82 & 15 & 80 \\
\hline 13 & 1-Octanol & $1-0$ clyl acelate & 10 & 83 & 30 & 85 \\
\hline 14 & & & 15 & 80 & 60 & 80 \\
\hline 15 & & & 8 & 85 & 15 & 87 \\
\hline 16 & & dc & 6 & 85 & 90 & 75 \\
\hline 17 & & & 1 & 90 & 5 & 82 \\
\hline 18 & & & 3 & 86 & 10 & 85 \\
\hline 19 & & & 1 & $70^{7 . h}$ & 85 & $80^{2 t h}$ \\
\hline
\end{tabular}

"Yield refers to isolated pure diacetate. 2.5 mmol of acetic anhydride was used. 
Acknow ledgement. We are thankful to Guilan University Research Council for the partial support of this work.

\section{References}

1. Green. T. W: Wuts. P. I. M. Protective Groups in Organic Smihesis. 3rd Ed.: Wiley: New York. 1999.

2. Hanson. J. R. Protecting Groups in Organic Sinthesis. Ist Ed: Blackwell Science. Inc.: Malden. M. A.. 1999

3. Stork G.: Takahashi. T.: Kawamoto. I.: Suzuki. T. J. Am. Chem. Soc. 1978, 100.8272.

4. Steglich. W.: Hofle, G. Angew. Chem.. Int. Ed. Engl. 1969.8, 981.

5. Review: Hötle. G.: Steglich. W: Vorbrüggen. H. Angew: (Them. Int. Ed. Engl. 1978. 17.569.

6. Kumareswaran. R.: Gupta. A.: Vankar. Y. D. Sinth. Conmun. $1997,27,277$

7. Vedejs. E.: Daugulis. O.J. Org. Chem. 1996,61,5702.

8. Ishihara. K: Kubota. M: Yamamoto. H. Smlet 1996. 265

9. Miyashita. M.: Shiina. I.: Myyoshi. S.: Mukaiyama. T. Bu/. Chem. Soc. Jpn. 1993.66.1516

10. Iqbal. J.: Srivastava. R. R. J. Org Chem. 1992.57. 2001.
11. Mukaiyama. T.; Shiina. I.; Myashita. M. Chem. Lett. 1992, 625

12. Saravanan1. P.: Singh. V. Tetrahedron Lett. 1999. 40. 2611.

13. Chauhan. K. K.: Forst. C. G.: Love. L.: Waite. D. Smlet 1999. 1743 .

14. Ishihara, K: Kubota. M.: Kurihara. H.: Yamamoto, H. J. Org. Chem $1996,61,4560$.

15. Reigo. J. M:- Sedin. Z.: Zaldivar, J. M.: Marziano, N. C.: Tortato. C. Tetrahedron Lett 1996. 37.513 .

16. Turro. N. T. Tetrahedron 1987. +3. 1589.

17. Zolfigol. M. A.: Bamoniri. A. Sylen 2002. 1621.

18. Zolfigol, M. A. Tetrahedron 2001,57.9509.

19. Zolfigol, M. A.: Shirini, F; Ghorbani Choghamarani. A.; Mohammadpoor-Baltork, I. Green. Chem. 2002. 4. 562.

20. Shirini. F.: Zoltigol. M. A.: Mohammadi. K. Phosphorus, Sulfw and Silicon and the Related Elentents 2003. 178. 1617.

21. Gauttret. P.: El-Ghamarti. S.: Legrand. A.: Coutrier. D.: Rigo. B. Simh Commun. 1996, 126.707.

22. Aldrich Catalogue. Handhook of Fine Chemicals. 1990-1991.

23. CRC Handbook of Chemistry and Phusics, 5tth Ed.: CRC Press: Boca Raton. 1973.

24. Beilstein Handbook of Organic Chemismy. 4th Ed.: Springer: Berlit1. 1988. 